\title{
Assessing Future Elementary Teachers' Pedagogical Content Knowledge in a Physics Class
}

\author{
Claudia Fracchiolla and N. Sanjay Rebello
}

Department of Physics, Kansas State University, 116 Cardwell Hall, Manhattan, KS 66506

\begin{abstract}
The nature of teacher's pedagogical content knowledge (PCK) has often been described as a personal construct that develops over years of practice. However, research has shown that some aspects of PCK can be developed during the preparation of pre-service teachers. A common thread among these aspects of PCK is the importance of kids' prior knowledge. At Kansas State University, a physics class was reformed to infuse PCK into the learning experience of future elementary teachers. As part of the class, students were required to develop a lesson plan that incorporated their understanding of kids' ideas about physics and how to address those ideas. To assess students' PCK, we searched for instances where kids' prior knowledge were present and how students incorporated these ideas into their lesson plan. We present the results of our study and implications for instruction.
\end{abstract}

Keywords: Pedagogical Content Knowledge.

PACS: $01.40 . \mathrm{Fk}$

\section{INTRODUCTION}

An ongoing discussion in K-12 STEM education has focused on a push for science early in schools, since there is a concern U.S. children are being outperformed by children in several other countries. The National Research Council (NRC) published a report which makes clear that to achieve better science school programs we need to develop good programs for training teachers: "Education reform would only be successful if teacher preparation is successful"1. The current structure of most science teacher preparation programs is that pre-service teachers receive content and pedagogical content in separate classes. In their pedagogical classes, they may learn about inquirybased teaching, but their content classes for the most part are taught in a traditional format. ${ }^{2-4}$ Therefore, most pre-service teachers have not received any formal instruction on how to implement inquiry-based teaching in their science classrooms.

There have been several efforts to implement a curriculum change that would allow for combining the pedagogical and content knowledge into one class for future teachers. Among the most popular are Physics by Inquiry $(\mathrm{PbI})^{5}$ and Physics for Elementary Teachers (PET). ${ }^{6}$ Both curricula emphasize conceptual development and reasoning skills.

These curricula not only enable future elementary teachers to learn science, but also to reflect on their own learning through a metacognitive process, ${ }^{7}$ and also to learn about how their future students may think and learn the same topics. These experiences prompt future teachers to reflect on how their own learning process is connected to that of elementary children.

Another model that has gained strength is Instructional Rounds. ${ }^{8}$ Analogous to clinical rounds at hospitals, Instructional Rounds have been identified as one of the practices of teacher preparation that is likely to have the biggest impact on future teachers. ${ }^{8}$ In Instructional Rounds, a small group of pre-service teachers observe a classroom with a coach. After the observation they have a debriefing meeting where they reflect on their own practice based on their observations. This model is not viable for large enrollment classes. However, research has shown that pre-service teachers that engage in activities where they have to discuss videos of elementary students learning science concepts also improve their attitudes towards science. ${ }^{9}$ Here we explore the idea of using videos of elementary kids talking about science to not only improve pre-service teachers' attitudes towards science, but to also integrate their knowledge of content and pedagogy.

\section{THEORETICAL FRAMEWORK}

The idea of combining content and pedagogical knowledge is not new. In the 1980s, Shulman and collaborators investigated how subject matter preparation translates into knowledge for teaching. ${ }^{10}$ They came up with the construct of Pedagogical Content Knowledge (PCK), which represents discipline-specific pedagogical knowledge; i.e. knowledge that goes beyond the disciplinary content into the knowledge for teaching that particular subject. 
It includes knowledge about how children learn the subject, prior ideas that children will bring to the classroom, and appropriate strategies to address these ideas and facilitate learning.

There have been discussions about the nature of PCK: asking whether it is a personal construct that develops over years of practice or if some aspects of PCK can be developed during preparation of preservice teachers. Driel et al. ${ }^{11}$ believe that there are some aspects of PCK that can be developed in preservice teachers, such as: orientation towards teaching, curriculum knowledge, knowledge of kids' prior understandings and knowledge of instructional strategies. $^{12}$

The goal of this study is to investigate the extent to which future elementary teachers' PCK is affected by interventions similar to those used by PET. Among the five categories mentioned above, the common thread is the understanding of the importance of kids' prior knowledge. In this project, we will focus explicitly on this particular aspect of PCK.

\section{CONTEXT OF STUDY}

We reformed a large enrollment physics class for pre-service elementary teachers at Kansas State University. in order to integrate PCK into the core of the course. ${ }^{13}$ The new design of the course is based on a model known as the pedagogical learning bicycle (PLB). ${ }^{14}$ The model combines content knowledge (CK) with the development of pedagogical content knowledge $(\mathrm{PCK})^{10}$ through metacognitive reflection (MR) as a bridge between learning content and pedagogy.

During the first week of PLB, students go through a regular 3E learning cycle -- Explore, Explain, and Elaborate -- learning the content knowledge ${ }^{1}$. In the second week of the bicycle, students also go through a $3 \mathrm{E}$ learning cycle, but are focused on the PCK necessary to teach physics. During the exploration phase, students are exposed to kids' ideas about science, by watching videos of kids learning the same concepts they are learning or other activities. In the explanation phase, students are exposed to literature on elementary children's ideas of science. Finally, during the elaboration phase, students are expected to design learning experiences and assessments to address children's ideas of science ${ }^{2}$.

The unreformed course, that was taught previously, did include activities such as viewing videos of kids learning science and being provided a summary of

\footnotetext{
${ }^{1}$ This is how the class was originally taught ${ }^{15}$

${ }^{2}$ See Reference 13 for more details on the reformed class
}

kids' ideas of science through the literature. However, the unreformed course did not use the PLB, rather it used a $3 \mathrm{E}$ cycle focusing only on content, with the pedagogical aspect (viewing kids' videos and lecturers on kids' ideas of science) added onto the contentfocused $3 \mathrm{E}$ cycle. In other words, the difference between the unreformed course and the reformed course was that the latter explicitly used PBL, while the former did not. The intent of the reformed course, as compared to the unreformed course, was to enable the future elementary teachers to see the connection between their experiences with the concepts they are learning and kids' experiences when they learned the same concepts. The objective was to help them understand their future roles as teachers in an elementary classroom, which the original course did not explicitly address. ${ }^{3}$

\section{METHODS}

The majority of students in the class are either in their first or second year of college, but most have completed a freshman course where they observed an elementary classroom. Therefore, they have been exposed to what goes on in an elementary classroom. On the other hand, the majority have had very limited exposure to physics or science classes in general.

\section{Assessment Task}

Students were organized in groups of three to five to work on a capstone project that involves creating a lesson plan for one of the topics learned during the semester. Students were instructed to design an age appropriate lesson plan that incorporated children's ideas about science in the particular topic they were presenting. During the last two weeks of class, each group was required to present an overview of their lesson plan to the entire class. Finally, each student had to write a critique of a specific group's lesson plan and presentation. Guidelines for the critique stated that they should look not only at the presentation, but feasibility of learning goals, alignment of lesson and assessment with goals, alignment of lesson and assessment with children's ideas of science and clarity.

To assess the level of PCK centered on kids' prior knowledge, we analyzed the lesson plan and critiques. We looked specifically for instances of students referring to children's ideas and the depth with which they used those ideas in their lesson plan or how they critiqued their peers' presentations and lesson plans. The reason why we used the lesson plan and critique is

\footnotetext{
${ }^{3}$ The unreformed class also exposed students to the videos of kids' ideas, but it was not embedded in the curriculum as in the reformed class.
} 
because these two sources of data alig with two different levels of Bloom's taxonomy. ${ }^{16}$ The lesson plan corresponds to the synthesis level, where students use what they had learned throughout the semester to design activities and assessments that would facilitate learning for the children, taking into consideration their prior ideas. The critique corresponds to the evaluation level of Bloom's taxonomy in that students assess the ideas of their peers. We developed a rubric to score the lesson plans ${ }^{13}$ and the critique (see Table 1).

To determine if the reforms of the course had impacted students' PCK, we compared data collected from the reformed course (Fall 2013) and the unreformed course (Fall 2011). The same instructor taught both courses, and students were administered the same assessments, with identical guidelines and resources. The only observed difference that could impact students' performance can be attributed to the explicit use of the bicycle instructional model (PLB).

TABLE 1. Rubric for scoring the level of PCK evidence demonstrated in the critiques.

\begin{tabular}{|c|l|}
\hline Level & \multicolumn{1}{c|}{ Description } \\
\hline 0 & $\begin{array}{l}\text { Student does not mention if the group } \\
\text { addressed or not children's prior ideas }\end{array}$ \\
\hline 1 & $\begin{array}{l}\text { Student mentions whether or not the group } \\
\text { used children's prior ideas in their design }\end{array}$ \\
\hline 2 & $\begin{array}{l}\text { Students discussed how the group did or did } \\
\text { not use children's prior ideas in their design }\end{array}$ \\
\hline 3 & $\begin{array}{l}\text { Student gives opinion about how children's } \\
\text { prior ideas were used in the design and if it } \\
\text { was appropriate or not }\end{array}$ \\
\hline
\end{tabular}

\section{RESULTS}

In fall 2011, we collected data from 110 students, comprising 27 groups (baseline or unreformed course). In fall 2013, we collected data from 144 students, comprising 42 groups. Results of the analysis for the project proposal are shown in Fig. 1.

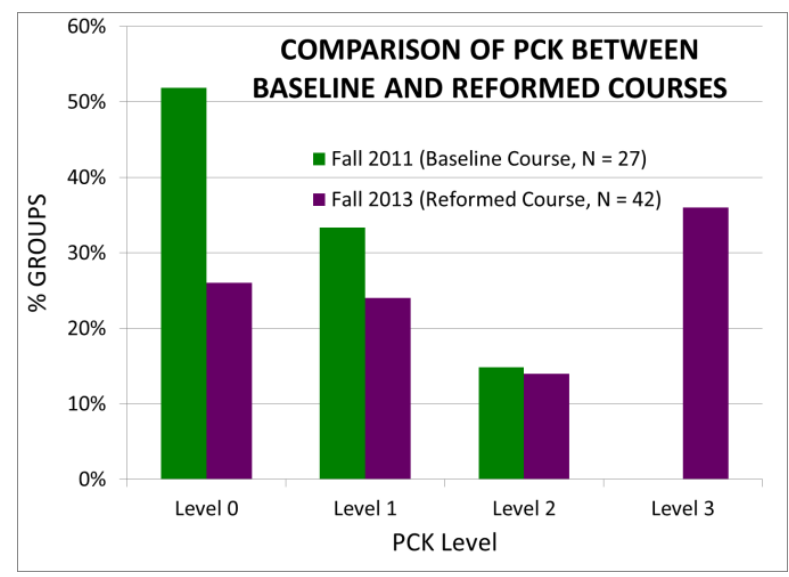

FIGURE 1. Comparison of the groups' PCK in the project proposal between baseline and reformed courses.

The majority of lesson plans $(85 \%)$ created by students in the baseline course fell into the level 0-1 of PCK. This means that $85 \%$ of the students did not mention children's ideas in their project or designs. On the other hand, half of the artifacts created by students in the reformed course fell into levels 2-3. This indicates that $50 \%$ of the groups included children's ideas in their designs and $36 \%$ of the groups included children's ideas in their designs and assessments.

We conducted a statistical analysis of the data using non-parametric Fisher's Exact test for comparing the reformed and unreformed classes. The results are shown in Table 2.

TABLE 2. Fisher's Exact test results for the lesson plans

Fisher's Exact Test Results For Lesson Plans

\begin{tabular}{l|l}
$\chi^{2}(3,69)=16.165$ & $\mathrm{p}=.001$
\end{tabular}

Results of the Fisher's test indicate that there is a statistically significant difference between the proportions of students in the various levels. We noticed that among the lesson plans created by students in the reformed class, those who discussed children's ideas also implemented some form of assessment according to those ideas; therefore the trend of the distribution is not perfectly incremental. There are fewer instances where students mentioned children's ideas in their designs and did not assess them than those who did. We attribute this tendency to the fact that students are more aware of children's ideas and how to implement them in their lesson plans.

For the critiques, we observed that $68 \%$ of the students in the baseline course fall into level 0 of the rubric, while $58 \%$ of students in the reformed course, in some way or another, attended to the use of children's ideas in their peers' designs. Results for the critiques are shown in Fig. 2. Again we conducted a Fisher's Exact test to ascertain the statistical significance of the observed changes. The results are shown in Table 3.

TABLE 3. Fisher's Exact test results for the critiques Fisher's Exact Test Results for Critiques \begin{tabular}{l|l}
$\chi^{2}(3,140)=19.91$ & $\mathrm{p}<.001$
\end{tabular}

Results of the Fisher's test indicate there is a statistically significant difference between the proportions of students in various levels. Specifically it indicates that the critiques created by students in the reformed course attended to children's ideas of science significantly more than the critiques created by students in the baseline course. 


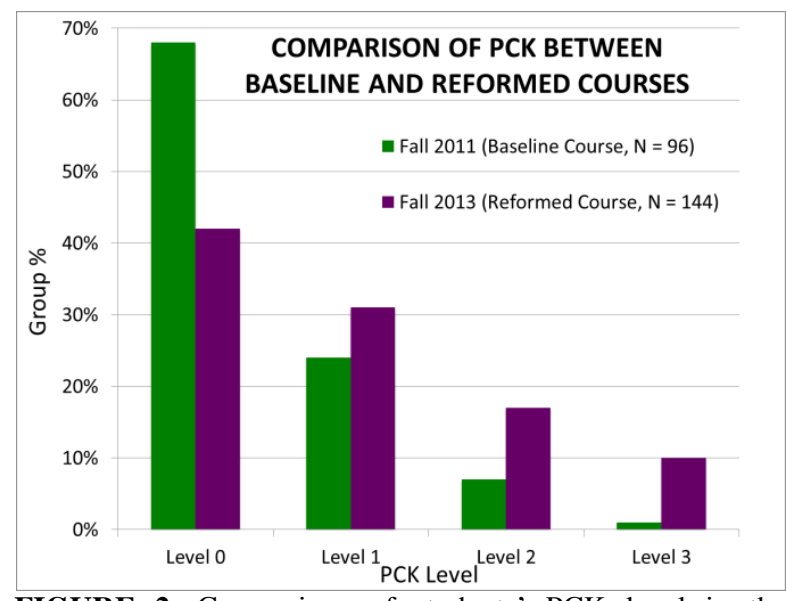

FIGURE 2. Comparison of students' PCK level in the critique between baseline and reformed courses.

\section{CONCLUSIONS}

It is widely accepted that PCK is an important component for preparation of future teachers. One of the most important aspects of PCK is knowledge of elementary kids' ideas of science. It is important for teachers to recognize the relevance of elementary kids' preconceptions and how to appropriately attend to these preconceptions as they design age-appropriate learning experiences for elementary kids. We modified a large enrollment class for future teachers to facilitate future elementary teachers to see the connection between their own learning experiences and the experiences of elementary school kids' they learn the same physics concepts.

The large enrollment $(\mathrm{N}>100)$ physics course at Kansas State University aims to infuse aspects of PCK to future elementary teachers' preparation by creating a two-week long sequence of two $3 \mathrm{E}$ cycles, called the PLB (pedagogical learning bicycle). In the first week of the PLB, students learn physics concepts through a 3E (explore-explain-elaborate) sequence. In the second week of the bicycle, students also go through another $3 \mathrm{E}$ learning cycle, but they now focus on pedagogical knowledge needed to teach the same physics concepts that they had learned in the previous week.

By implementing PLB as an instructional model to combine content and pedagogy, we observed a significant enhancement of students' understanding of the of kids' prior knowledge, which is an important aspect of PCK. This means that students in the reformed class were more likely to incorporate children's ideas into their lesson plans. They were also more likely to attend to children's prior ideas when evaluating their peers' lesson plans. Further research is needed to determine the exact mechanisms that facilitate the process which results in improvement of this aspect of the pre-service teachers' PCK.

\section{ACKNOWLEDGMENTS}

This material is based upon work supported by the National Science Foundation under Grant No. 114085. Any opinions, findings, and conclusions or recommendations expressed in this material are those of the authors and do not necessarily reflect the views of the National Science Foundation.

\section{REFERENCES}

1. National Research Council, National Science Education Standards. (National Academy Press, Washington, D.C., 1996).

2. P. D. Hurd, Sci. Educ. 67 (1), 57-67 (1983).

3. P. Tamir, Sci. Educ. 67 (5), 657-672 (1983).

4. R. E. Stake and J.A. Easley, Case Studies in Science Education (U.S. Government Printing Office, Washington, DC, 1978).

5. L. C. McDermott, Physics by Inquiry, Vols. I \& II (Wiley, New York, NY, 1996).

6. F. M. Goldberg, S. Robinson, and V. Otero, Physics for Elementary Teachers (It's About Time, Armonk, NY, 2006).

7. J. H. Flavell, Am. Psychol. 34 (10), 906-911 (1979).

8. E. A. City, R.F. Elmore, S.E. Fiarman, and L. Teitel, Instructional Rounds in Education: A Network Approach to Improving Learning and Teaching. (Harvard Education Press, Cambridge, MA, 2009).

9. D. B. Harlow, L. H. Swanson, H. A. Dwyer, and J.A. Bianchini, "Learning Pedagogy in Physics" in 2010 Physics Education Research Conference, edited by C. Singh et al., AIP Conference Proceedings 1289, American Institute of Physics, Melville, NY 2013, pp. 161-164.

10. L. S. Shulman, Educ. Res. 15 (2), 4-14 (1986)

11. J.H. Van Driel, D. Beijaard, and N. Verloop. J. Res. Sci. Teach. 38, 137 (2001).

12. E. Etkina, Phys. Rev. ST Phys. Educ. Res. 6, 020110 (2010).

13. N. S. Rebello and D. Zollman, presented at the Physics Education Research Conference 2013, Portland, OR, 2013.

14. R. J. Karplus, Journal for Research in Science Teaching, 12, 213-218 (1974).

15. D. A. Zollman, Phys. Teach. 28 (1), 20-25 (1990).

16. B.S. Bloom, M.D. Engelhart, E.J. Furst, W. H. Hill, and D.R. Krathwohl, Taxonomy of Educational Objectives: The Classification of Educational Goals. Handbook I: Cognitive Domain (David McKay Company, New York: 1956). 